\title{
MICROBIOLOGICALLY INFLUENCED CORROSION IN THE FERMILAB MAIN INJECTOR MAGNET LOW CONDUCTIVITY WATER SYSTEM*
}

\author{
$\underline{\text { P. G. Hurh }}{ }^{\#}$, N. Kubantseva, M. P. May, FNAL, Batavia, IL
}

\begin{abstract}
In mid-November of 1997, numerous pinhole leaks in the new 304L stainless steel header piping of the Main Injector Magnet Low Conductivity Water System (MI LCW) were discovered. Metallurgical and biological analysis of the extensive corrosion damage in the welded areas of the piping revealed that microbiological organisms played a key role in the corrosion process. The resulting massive repair efforts included microbe eradication (through chemical biocides), damage assessment (through biological and metallurgical analysis, radiography, and internal remote video inspection), pipe cleaning (through custom designed mechanical cleaning devices), weld repair (through weld overlay), and microbiological control during system start-up (through ultra-violet radiation and heat treatments). Multiple contributing factors leading to the corrosion problems were identified, including poor welding practice (inadequate technical specifications and inspection), improperly treated fill water, and insufficient water flow for extended periods of time (several months) prior to system use. Lessons learned from these experiences will be of extreme importance to the design of similar cooling systems in the future.
\end{abstract}

\section{INTRODUCTION}

The MI LCW System consists of 6 above ground pumping stations distributed around the MI ring supplying cooling water to the bus of all magnets in the tunnel $(650+$ magnets). Only the stainless steel header piping was affected by the corrosion problems.

All of the piping components are 304L stainless steel welded with $308 \mathrm{~L}$ filler metal. The majority of piping is seam welded 6-inch nominal pipe size, schedule 10 pipe with larger piping in the pumping stations. The system has approximately 5,400 welded joints. Total water volume for the system is approximately 66,000 gallons.

Each pumping station includes a large heat exchanger (also 304L) and a de-ionizing (DI) and filtering circuit. All 6 pumping stations are connected through the tunnel via the 6-inch headers. One pumping station (MI-60) includes a fill station and a 3,000-gallon reservoir tank. The design operating pressure of the system is $150 \mathrm{psi}$.

\footnotetext{
*Work supported in part by the U.S. Department of Energy under contract No. DE-AC02-76CH3000.

${ }^{\#}$ Email: hurh@fnal.gov
}

In mid-November of 1997, evidence of a severe corrosion problem in the MI Magnet LCW System was observed. Leaks in the new stainless steel header system became apparent during start-up operations, some months after hydrostatic pressure testing. Engineering consultants immediately diagnosed the problem as Microbiologically Influenced Corrosion (MIC). This paper is an abbreviation of a report which describes the repair efforts, identifies some of the causes of the MIC problem, and makes some recommendations for prevention of MIC in the future [1].

\section{DETECTION \& STABILIZATION}

The first sector of the MI Magnet LCW System was filled with chlorinated well water on May 29, 1997, for the purposes of hydrostatic testing of the completed piping. Each remaining sector was then filled by "pushing" the test water from the first sector with new well water. In this manner the entire system was filled and pressure tested over a period of 6 months. Between fills, the water was allowed to remain static in the tested piping.

When circulation pumps were started in November, several pinhole-sized leaks were discovered on the weld joints of the LCW piping. Although the vast majority of leaks were observed on welds, several leaks were also found as far as one inch from the nearest weld joint. In a few days, the number of leaks multiplied to almost 400 . From visual inspections of the leaks and bacteria tests conducted on water samples (high levels of aerobic/low nutrient bacteria and trace levels of sulfate reducing and iron-related bacteria were found), expert consultants suggested the cause of the leaks was MIC.

\subsection{MIC Description}

Microbiologically Influenced Corrosion is a phenomenon whereby corrosion of a surface is induced and/or accelerated by the presence of microbiological organisms. One description of the MIC mechanism to failure is as follows: A thick biofilm (layer of live bacteria) develops on a susceptible metal surface. The microorganisms develop colonies and form nodules (biomasses containing microbiological/corrosion by-products and deposits). These formations can trap ions and occlude the metal surfaces directly beneath them from oxygen dissolved in the water. Thus the nodules can create localized physical and chemical gradients at the metal surface, which initiate corrosion cells (such as a differential aeration cell). The electrochemical process dissolves metal beneath the biomass and a localized pit is formed [2]. 
The MIC corrosion process is very similar to crevice corrosion. In crevice corrosion, corrosion is often initiated by the creation of an oxygen or ion concentration cell. Stagnant water in a crevice cannot supply oxygen to maintain a passive oxide layer in the crevice. As oxygen is consumed in the crevice by the corrosion reaction, the water in the crevice becomes depleted of oxygen while oxygen is still available in the water at the mouth of the crevice. This creates a differential aeration cell accelerating the corrosion further. Corrosion rates for MIC can be greater than that for crevice corrosion because of the smothering coverage of the large biomass. Also, byproducts of some bacteria growth are acidic, accelerating the localized pitting even further. Some case histories report through-wall pitting of stainless steel pipes in a few months. One of these reported an effective corrosion rate of 0.055 inch per month for a 308 stainless steel weld [3].

\subsection{Stabilization and Damage Assessment}

After preliminary confirmation of MIC, biocides (glutaraldehyde and quaternary ammonium compounds) were added to control the bacteria growth. The system was drained and then dried using high-speed blower fans.

Each accessible weld in the entire system was labeled. Damage assessment was performed through two methods, radiographic examination and internal visual inspection.

$10 \%$ (208) of the accessible welds were radiographed. Of these, $61 \%$ showed flaws that could be associated with MIC (deep pitting or tunneling). Most of the welds also showed flaws suggesting poor welding practice (incomplete fusion/penetration, etc.)

Internal visual inspection of the piping was accomplished using custom designed and fabricated remotely operated video camera devices. The most useful design utilized a radio controlled gimbal mount to aim the camera in both yaw and pitch. Using this device, operators were able to videotape all accessible welds in the system.

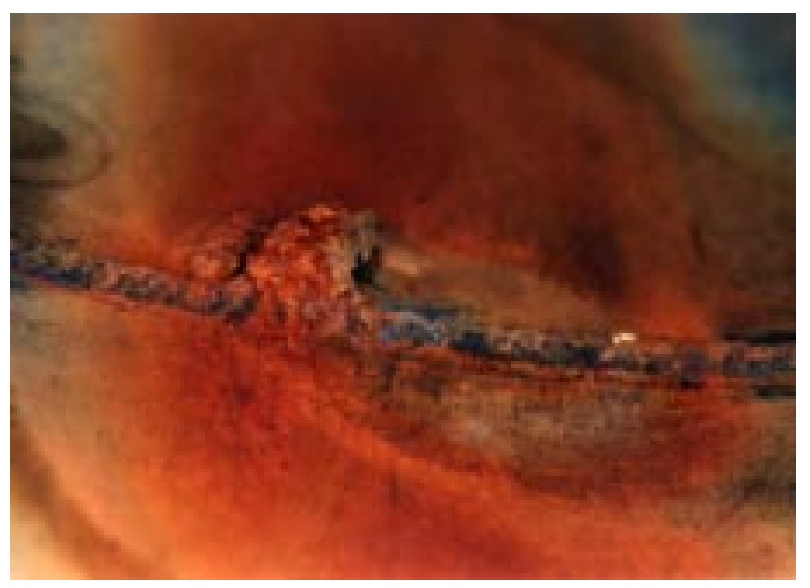

Figure 1: Typical corrosion site on MI LCW pipe weld.

The internal visual inspection revealed that almost every weld in the piping exhibited signs of advanced corrosion. Most welds had orange colored streaks flaring out from tack welds that had not been consumed by the final weld pass. A majority of welds had a build up of corrosion byproduct (and MIC nodules) in several places on each weld. Some of the nodules were crumbled and/or knocked off by the passage of the camera device. The worst damage was usually at the bottom of the pipe.

\section{RECOVERY EFFORTS}

While the MIC situation was stabilized, research and development explored recovery options. Weld repair and pipe-cleaning techniques were researched and compared.

\subsection{Weld Repair}

Repair techniques considered ranged from cutting out and replacing bad welds to patching bad welds with epoxy/fiberglass wraps. Repair options were tested and compared in categories such as longevity, serviceability, ease of application, and cost. Our comparison led us to choose a combination of repair methods to apply to welds in various locations and in various conditions.

The most widely used repair method was to remove the crown of the old, defective weld and then overlay with a new weld (316L stainless steel filler material). In this manner, the existing weld metal was re-fused and a new crown layer was added. In addition, the entire weld area was exposed to high temperature during welding which helped sterilize any remnant bacteria.

Detailed technical specifications were written for each of the weld repair methods. These specifications and the results from metallurgical evaluations of the test repairs were reviewed positively by welding engineers and metallurgists. In addition, stringent procedures for welder qualification and quality control were implemented to ensure consistent quality throughout the weld repairs.

On March 2, 1998, welders and pipe fitters arrived on site. The workers attended meetings to learn the weld repair techniques and review specifications. Field testing of welders was begun immediately, and the first weld repairs were made on March 3, 1998.

As weld repairs progressed, inspection of the work was performed and results recorded in a weld database. Technicians trained by Fermilab's Weld Shop, performed visual examinations of each weld and weld repair within one day after they were made. In addition, suspect welds were visually examined internally using the remote video devices. As sectors of piping were completed, 5\% radiography and $100 \%$ pneumatic bubble tests were performed to ensure quality.

\subsection{Pipe Cleaning}

Although the addition of biocides and draining/drying of the pipes presumably halted the MIC process, complete mitigation required the removal of the entire MIC habitat. Deposits in the pipe, in the form of nodules and tubercles, were tenaciously adhered to the pipe walls and could not be removed by water circulation alone. These deposits, besides harboring bacteria, could have been sites for future 
infestations. Thus, removal of as much MIC deposit as possible was considered necessary to leave a passivated stainless steel surface that would resist future corrosion.

Initially consultants suggested using a $20 \%$ nitric and $4 \%$ hydroflouric acid combination to remove the deposits and heat tint completely. Treatment using such a harsh etchant in large volumes created safety and health concerns along with schedule and cost concerns. Therefore, mechanical cleaning methods were developed using custom devices that were inexpensive and effective.

These devices all utilized spinning sets of abrasive pads (silicon carbide) driven by air motors. One device consisted of a spinning abrasive disk and an air motor mounted on spring-loaded wheels. This device was designed to be pulled through the pipes and buff the entire pipe inner surface including welds. A more sophisticated device design utilized a digital video camera to allow the operator to locate the cleaning pads on the dirty welds.

These devices eliminated all discoloration, both from heat tint and MIC deposits, on the pipe inner surface. In order to ensure that our techniques were adequate to protect against future corrosion, a microbiologist and a metallurgist reviewed the mechanical cleaning method and approved of its use.

After completing repairs, the piping was filled sector by sector with filtered and UV treated water and then hydrostatic pressure tested (225-psi). Pressure testing found several leaks (17 out of about 4000 weld repairs). These leaks were repaired and re-tested successfully.

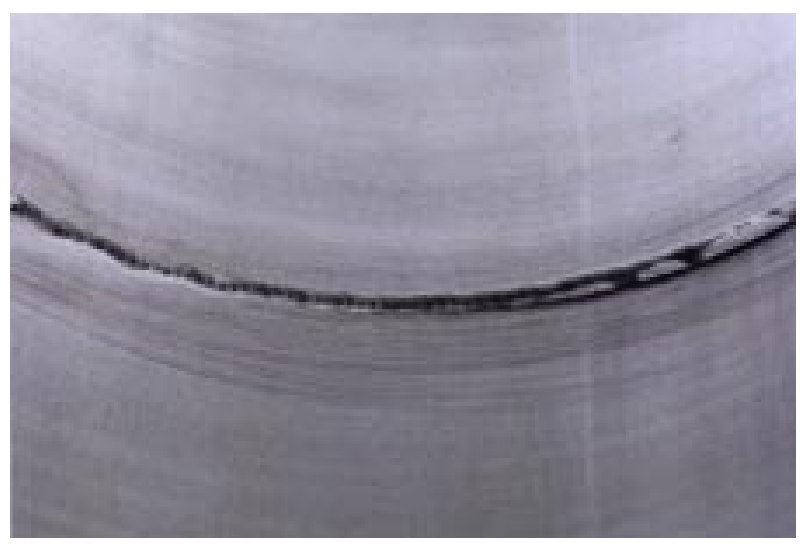

Figure 2: Mechanically cleaned SS pipe weld.

\section{CAUSES \& RECOMMENDATIONS}

Observations made during damage assessment suggest two direct causes of our MIC problem. One is simply the fact that low quality water was allowed to stand in sections of the piping system for extended periods of time. This allowed thick biofilms and nodules to grow on the pipe interior since insufficient water velocity was present to shear away the biofilms as they formed. The other is the poor corrosion resistance of the piping welded areas that existed due to improper welding practices during initial installation. Excessive heat, incomplete penetration and fusion and high heat input, among other defects, encouraged localized corrosion and played a large role in the susceptibility of the welds to MIC attack.

Both direct causes stem from one root cause, the lack of awareness of MIC dangers. The original piping designers, fabricators, and operators were unaware of the problems that MIC can cause in piping systems. Specifying corrosion resistant materials and final water quality will not ensure corrosion prevention or abatement. Start-up, lay-up, and maintenance operations must also be addressed.

Preventative measures which help a piping system resist MIC can be employed. These include chemical treatment, heat treatment, ultra-violet radiation, deionization and filtering, and maintaining fluid velocity [4]. In the case of the MI LCW System, we initially heat treated our piping system to 135 degrees $F$ in an attempt to sterilize the system. Then new water added to the system was sterilized using commercially available UV disinfection units. De-ionization and filtering was begun immediately after filling to maintain ultra-pure water. Procedural constraints were implemented limiting low flow conditions to a maximum of 5 days. Finally, monitoring of the system is achieved using custom designed MIC coupons which act as an early warning system of future MIC attack.

Our experiences have shown that corrosion, especially MIC, should be addressed early in the design process. Besides obvious issues such as material selection and water quality, the water system designer should consider compatibility with heat treatment and biocides during the design process. Welding technical specifications should describe acceptable welding practice in detail plus fully explain mandatory inspection requirements. Start-up and lay-up guidelines and/or procedures should be written and enforced with corrosion problems in mind.

\section{ACKNOWLEDGEMENTS}

Although it is not possible to thank everyone here, we would like to acknowledge the following Fermilab personnel: B. Autro, M. Ball, D. Capista, H. Casebolt, R. Ducar, R. Farritor, J. Finks, B. Fritz, C. Gattuso A. Germain, B. Hanna, R. Hiller, B. Hoffman, S. Holmes, T. Johnson, F. Juravic, P. Martin, P. Mazur, G. Pewitt, D. Plant, J. Roberts, J. Satti, T. Schmitz, B. Slazyk, B. Smith, I. Stauersboll, L. Vonasch, and K. Williams.

\section{REFERENCES}

[1] Hurh, P. G., "Microbiologically Influenced Corrosion in the MI Magnet LCW System; Case History and Final Recommendations", MI Technical Note \#0254, FNAL, Batavia, IL, (1999)

[2] Borenstein, S.W., Microbiologically Influenced Corrosion Handbook, Woodhead Publishing, Cambridge, p. 4, (1994).

[3] Chung, Y., Mantle, H.J., Lasko, G.E., 'Selective Attack in Microbiologically Influenced Corrosion of UNS S30800 and S32100 Welds', Corrosion/95, 13-1, NACE, Houston, TX, (1995).

[4] Husted G.R., 'Sanitization: A Comparison of Different Sanitants Used in Microelectronics High-Purity Water Systems', Ultrapure Water, Jan, (1998). 